\title{
COVID-19 and mental health: Our reactions to its actions
}

Mohd. Farooq Shaikh ${ }^{1, *}$ and Faiz Ahmed Shaikh ${ }^{2}$

\author{
${ }^{1}$ Neuropharmacology Research Strength, Jeffrey Cheah School of Medicine and Health Sciences, Monash \\ University Malaysia, Bandar Sunway 47500, Selangor, Malaysia. \\ ${ }^{2}$ School of Pharmacy, Management and Science University, Shah Alam, Selangor, Malaysia. \\ * Correspondence: farooq.shaikh@monash.edu; Tel.: +603-55144483
}

Published: 4 April 2020

https://doi.org/10.31117/neuroscirn.v3i2.46

Keywords: COVID-19; pandemic; mental health

C2020 by Shaikh and Shaikh for use and distribution in accord with the Creative Commons Attribution (CC BY-NC 4.0) license (https://creativecommons.org/licenses/by-nc/4.0/), which permits unrestricted non-commercial use, distribution, and reproduction in any medium, provided the original author and source are credited.

The genetic epidemiology suggests that coronavirus disease 2019 (COVID-19) is most likely transmitted to the human population in November or December 2019, originating from Wuhan and spread entirely by human-to-human transmission. The period of the Chinese New Year holidays is thought to be one of the key periods where a substantial transmission took place within Wuhan. Moreover, the movement of people from Wuhan resulted in massive spread nationally and internationally when people traveled during the holidays (Heymann \& Shindo, 2020).

WHO declared COVID-19 as a pandemic on $11^{\text {th }}$ March 2020 , which by that time, had already spread to about 114 countries with 118,000 cases, killing 4,291 people globally. This is the time when the cases outside China had increased by 13-fold, and the number of countries affected had tripled. WHO was extremely careful in using the word pandemic as it may cause unnecessary fear, suffering, and loss of life if the pandemic declaration was made before it was indispensable to raise such alarm. As per World Health Organization (WHO), "If countries detect, test, treat, isolate, trace, and mobilize their people in the response, those with a handful of cases can prevent those cases becoming clusters, and those clusters becoming community transmission." (World Health Organization, 2020b)

A country like South Korea leads by example via early aggressive action on detection and testing in all the possible pretentious populations irrespective of symptoms to contain the spread at a community level. United Arab Emirates (UAE) was also commendable by conducting extensive screening from the outset. As of 20 March 2020, South Korea performed 316,664 tests, which are highest by any country. In terms of tests performed per million people, UAE is leading with 12,738 as of 16 March 2020. At the same time, population by country is also an essential factor in the containment of the infection. Populations in Singapore, South Korea, and UAE are relatively smaller compared to China. South Korea and Italy are ideal countries in terms of the population size for comparison. South Korea's over-preparedness paid off well as they were able to contain the infection to around 9,037 positive cases compared to Italy's 69,176 cases, with over 8,326 deaths, which were the highest death in one country with COVID-19 as of 25 March 2020.

Dr. Lisa Rosenbaum, who is a national correspondent for the New England Journal of Medicine, clearly said that governments must be transparent and comprehensive on the seriousness of the issue to attain public trust and support. She mentioned, "Around the world - from muzzled doctors in China to false promises of testing capacity in the United States, to refutations of resource-rationing claims in Italy we are seeing that denial is deadly. The point at which preparedness dissolves into panic will always be context-dependent. But the tragedy in Italy reinforces the wisdom of many public health experts: the best 
outcome of this pandemic would be being accused of having overprepared." (Rosenbaum, 2020).

Mental health is one of the biggest problems which needs to be addressed now, and post-COVID-19 pandemic as this crisis has generated tremendous stress in public. Lockdowns, the spread of fake news, and poor understanding of the seriousness have contributed to it. Lack of knowledge and misinformation has created havoc in the society. One example is the availability and usage of the mask created a lot of stress and anxiety.

Due to a global shortage of masks at the beginning of the COVID-19 outbreak, the health authorities other than China had a different recommendation. Some health authorities advised citizens not to wear masks if they are not ill (e.g., Singapore). Others advised their citizens to wear masks and use sanitizers (e.g., Malaysia, Vietnam). Later on, WHO advised healthy people, to wear masks only if they are coughing or sneezing or taking care of a person with suspected COVID-19 infection (World Health Organization, 2020a). According to a study conducted in China, wearing masks lowers anxiety and depression levels (Wang et al., 2020). As per WHO wearing a mask regardless of the presence or absence of symptoms can extend psychological benefits by offering a sense of security.

Any outbreak will have a significant psychological impact on people. It can precipitate new psychiatric symptoms in healthy individuals and worsen the condition in people with pre-existing mental illness. This can also cause anxiety among caregivers of the affected individuals (Hall et al., 2008). Even the unaffected population may experience helplessness and become suspicious towards others who are ill. People may develop fear and anxiety about being sick or dying, possibly causing a nervous breakdown. A suspected COVID-19 patient killed himself in Malaysia, and his pre-existing depression is considered to be a contributor.

Psychiatric morbidities have been found to vary from anxiety, depression, panic attacks, somatic symptoms, posttraumatic stress disorder, delirium, psychosis and even suicidality (Hall et al., 2008; Müller, 2015; Tucci et al., 2017), which have been associated with an increased self-blame (Sim et al., 2010). Those who are quarantined may feel shame, guilt, or might face stigma. The prevalence of psychological distress is reported to be high among those who had a longer duration of the quarantine. This prolonged duration is also associated with an increased prevalence of posttraumatic stress disorder symptoms (Hawryluck et al., 2004). The inability to get closer to loved ones results in anger and displeasure, and those with a sudden loss of their loved ones due to the outbreak leads to grief and trauma (Shear, 2012).

Moreover, several cases were reported where the Chinese community was targeted in European countries as well as in the USA. Politicians made irresponsible statements and labeling it as a Chinese virus, which is extremely discriminatory. North-east Indians also faced discrimination from other Indians on the COVID-19 issue as they have some similarities in looks like that of Chinese. Malaysia also discriminated against one or other religious group who caught up with COVID-19 infection. These incidences have a significant impact on the mental health and social wellbeing of the individuals and the community. This could lead to distrust towards individuals, government, and healthcare services in terms of their capability to contain the outbreak and to treat it. The collapse of industries, financial losses, and unemployment risk is further enhancing the negative emotion of the affected individuals (Van Bortel et al., 2016).

The COVID-19 pandemic could endanger the mental well-being of the healthcare workers, causing depression, anxiety, insomnia, or distress. Many of the healthcare staff were found to be psychologically depressed in a survey among healthcare workers in 34 hospitals exposed to COVID-19 in China. The intensity of depression was higher among frontliners who were directly involved in the diagnosis, treatment, or provision of nursing care to patients with suspected or confirmed COVID-19 (Lai et al., 2020). A sustained rise in COVID-19 cases, excessive workload, inevitable media coverage, and inadequate personal protective equipment and medications were among the various factors for the deterioration of mental health. Healthcare workers are not only afraid of getting infected but also worried about contaminating their families, friends, and colleagues with the virus (Lai et al., 2020). The Italian nurse who committed suicide with the fear that she could be responsible for further spreading is an example of it.

In conclusion, transparency and truthfulness towards the seriousness of the problem are the only way to gain public trust in the fight against COVID-19. Safeguarding both the physical and mental wellbeing of health care staff is an essential component of public 
health initiatives. Breakdown of the frontliners could lead to chaos in the healthcare system. Boosting up the morale of common public and healthcare providers is extremely important. An immediate measure should be taken to provide mental and psychosocial support services to vulnerable people and healthcare workers.

\section{References}

Hall, R. C. W., Hall, R. C. W., \& Chapman, M. J. (2008). The 1995 Kikwit Ebola outbreak: lessons hospitals and physicians can apply to future viral epidemics. General Hospital Psychiatry, 30(5), 446-452.

https://doi.org/10.1016/i.genhosppsych.2008.05.003

Hawryluck, L., Gold, W. L., Robinson, S., Pogorski, S., Galea, S., \& Styra, R. (2004). SARS control and psychological effects of quarantine, Toronto, Canada. Emerging Infectious Diseases, 10(7), 1206-1212. https://doi.org/10.3201/eid1007.030703

Heymann, D. L., \& Shindo, N. (2020). COVID-19: what is next for public health? In The Lancet (Vol. 395, Issue 10224, pp. 542545). Lancet Publishing Group. https://doi.org/10.1016/S0140-6736(20)30374-3

Lai, J., Ma, S., Wang, Y., Cai, Z., Hu, J., Wei, N., Wu, J., Du, H., Chen, T., Li, R., Tan, H., Kang, L., Yao, L., Huang, M., Wang, H., Wang, G., Liu, Z., \& Hu, S. (2020). Factors Associated With Mental Health Outcomes Among Health Care Workers Exposed to Coronavirus Disease 2019. JAMA Network Open, 3(3), e203976. https://doi.org/10.1001/jamanetworkopen.2020.3976

Müller, N. (2015). Infectious diseases and mental health. Key Issues in Mental Health, 179, 99-113. https://doi.org/10.1159/000365542

Rosenbaum, L. (2020). Facing Covid-19 in Italy - Ethics, Logistics, and Therapeutics on the Epidemic's Front Line. The New England Journal of Medicine. https://doi.org/10.1056/NEJMp2005492

Shear, M. K. (2012). Grief and mourning gone awry: Pathway and course of complicated grief. Dialogues in Clinical Neuroscience, 14(2), 119-128.

Sim, K., Huak Chan, Y., Chong, P. N., Chua, H. C., \& Wen Soon, S. (2010). Psychosocial and coping responses within the community health care setting towards a national outbreak of an infectious disease. Journal of Psychosomatic Research, 68(2), 195-202. https://doi.org/10.1016/i.jpsychores.2009.04.004

Tucci, V., Moukaddam, N., Meadows, J., Shah, S., Galwankar, S. C., \& Kapur, G. B. (2017). The Forgotten Plague: Psychiatric Manifestations of Ebola, Zika, and Emerging Infectious Diseases. Journal of Global Infectious Diseases, 9(4), 151-156. https://doi.org/10.4103/igid.jgid 6617

Van Bortel, T., Basnayake, A., Wurie, F., Jambai, M., Koroma, A. S., Muana, A. T., Hann, K., Eaton, J., Martin, S., \& Nellums, L. B. (2016). Psychosocial effects of an Ebola outbreak at individual, community and international levels. Bulletin of the World Health Organization, 94(3), 210-214. https://doi.org/10.2471/BLT.15.158543

Wang, C., Pan, R., Wan, X., Tan, Y., Xu, L., Ho, C. S., \& Ho, R. C. (2020). Immediate psychological responses and associated factors during the initial stage of the 2019 coronavirus disease (COVID-19) epidemic among the general population in China. International Journal of Environmental Research and Public Health, 17(5). https://doi.org/10.3390/ijerph17051729

World Health Organization. (2020a). When and how to use masks. https://www.who.int/emergencies/diseases/novelcoronavirus-2019/advice-for-public/when-and-how-to-use-masks

World Health Organization. (2020b). WHO Director-General's opening remarks at the media briefing on COVID-19 - 11 March 2020. https://www.who.int/dg/speeches/detail/who-director-general-s-opening-remarks-at-the-media-briefing-oncovid-19---11-march-2020 